\title{
Determining the Drive Power of the System Controlling the Vibration Amplitude of the Rectifiers for the Continuously Variable Mechanical Transmission with Internal Force Functions
}

\author{
Vladislav Soldatkin ${ }^{1}$, Alexey Tereshin ${ }^{1}$, and Andrey Yurkevich ${ }^{1, *}$ \\ ${ }^{1}$ Institute of Engineering Science, Ural Branch of the Russian Academy of Sciences, 34, \\ Komsomolskaya St., 620049, Ekaterinburg, Russia
}

\begin{abstract}
The article discusses the choice of the power and type of the drive motor for the system controlling the vibration amplitude of the rectifier rocker arms of the continuously variable mechanical transmission, intended for use on a motor vehicle. Formulas for calculating the required torque and rotational speed of the drive motor with a planetary differential control gear are given. It is shown that the use of an electrohydraulic drive provides the required speed and power operation of the control system. The results of the system testing are presented.
\end{abstract}

\section{Introduction}

The driving control of the motor vehicle which transmission is equipped with the continuously variable mechanical transmission with oscillatory movement of internal links and force function control (the Blagonravov transmission) $[1,2,3]$ is maintained in the following manner. The driver, pressing the control pedal, first increases the vibration amplitude of the rocker arms of the mechanical rectifiers. In this case, while the vehicle doesn't move ('stop' mode of the transmission), the rear ends of the torsion bars connected to the driven shaft of the transmission are motionless, and the front ends rotate together with the rocker arm in the working direction of the active rectifier. As a result, the torsion bars are subjected to twisting. The twisting of the torsion bars creates a force function [4]. In addition to the above, the maximum torque, proportional to the sum of the average torques over the period is developed on the transmission driven shaft. The work [3] considers the specifics of automatic regulation of such transmission installed on the prototype vehicle [5] in detail.

Since the internal combustion engine (ICE) turns out to be unloaded in the 'stop' mode $[1,6]$, the twisting of the torsion bars (creation of force functions) can be provided only due to the work performed by the drive motor of the control system. This is the most energyconsuming drive operation mode. The force function can be adjusted by moving the control

*Corresponding author: urkeva@mail.ru 
element, the position of which determines the vibration amplitude of the rectifier rocker arms. In this case, both the value of the required torque and the rate of amplitude change should be provided. The work [7] provides data for friction variators, in which the speed of changing the gear ratio from min to max is $1.5 \ldots 2 \mathrm{sec}$. Thus and so, we will focus on these values when it comes to the Blagonravov transmission. The speed of the control system will depend on the selection of the kinematic scheme of the mechanism $[8,9,10]$, the type and characteristics of the drive motor.

The objectives of this paper are to substantiate a reasonable choice of the power and type of the drive motor for the engineering prototype of the Blagonravov transmission with a planetary differential control gear [6] and to carry out a comparative analysis of the test results of the transmission with electric and electrohydraulic control drives.

\section{Estimation of the required drive power of the control system}

The amount of work performed by the drive motor of the control system should provide the driver-set vibration amplitude of the rectifier rocker arms $\varphi_{0}$. In the 'stop' mode, it will correspond to the work required for twisting the transmission torsion bars at the mean twist angle $\varphi_{t s}$ per one revolution of the drive shaft. With a harmonic generator [1], the angle $\varphi_{t s}$ is equal to the vibration amplitude $\varphi_{0}$ of the rectifier rocker arms in this mode. Let us make use of the characteristic of the force function - the work required on its creation depends only on the initial and final deformations of the elastic element [4]. Therefore, the work A required for this is equal to the total potential energy of the twisted torsion bars and does not depend on the kinematics of the control gear. This work is equal to

$$
A=n c_{t} \varphi_{t s}^{2} / 2 \text {, }
$$

where $n$-number of torsions;

$c_{t}$ - torsion bar stiffness.

Then the required power of the drive motor will be determined by the equation

$$
N_{d}=A / \Delta t \eta
$$

where $\Delta t$ - amplitude setting time;

$\eta$ - efficiency of the kinematic chain from the rocker arms of the rectifiers to the drive motor.

The expression (2) for the specific kinematic diagram of the control gear can be written as

$$
N_{d}=M_{d} \omega_{d} / \eta
$$

where $M_{d}$ - torque on the motor shaft;

$\omega_{d}-$ motor shaft rotation frequency.

Figure 1 demonstrates the kinematic diagram of the planetary differential control gear for the engineering prototype of the Blagonravov transmission. The principle of operation of the control gear and the distribution of loads over its elements are given in detail in [6]. The diagram is supplemented with a worm gear 6 , designed to control the rotation of the epicyclic gearing $z_{2}$ of the first planetary gear set. Two alternative modifications for the gearbox drive are considered: with a stepper motor 7 , directly connected to the worm (diagram I) and an electrohydraulic drive (diagram II). In the second modification, the stepper motor 7 controls the hydraulic valve 11 . The hydraulic part of the circuit includes a hydraulic pump 9, which is connected through a belt drive 13 to the ICE shaft 8 . The 
hydraulic motor 10 is rigidly connected to the gearbox worm 6 . When the driver presses the control pedal, the stepper motor 7 controls the hydraulic valve 11, which opens the channels that provide the rotation of the hydraulic motor in the right direction. In this case, the hydraulic lock 12 holds up the hydraulic motor 10 at the installed position, keeping it from from spontaneous rotation under load.

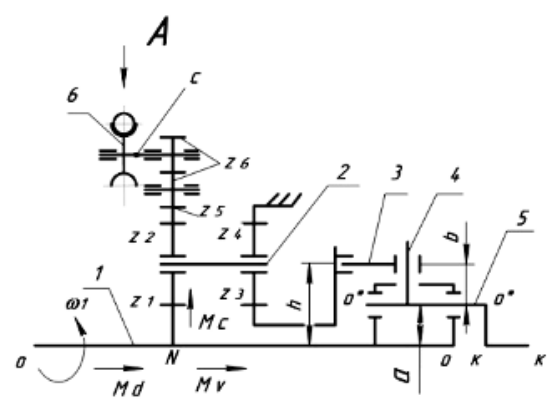

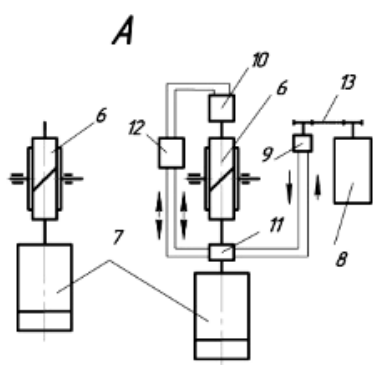

(11)

Fig. 1. Kinematic diagram of the planetary differential control gear for changing the vibration amplitude of the rocker arms of the rectifiers with a drive. I - modification of the drive with a stepper motor; II - modification of the drive with an electrohydraulic drive. 1 - drive shaft; 2 - general carrier; 3 - rocker arm link; 4 - guide; 5 - crank shaft; 6 - worm gear; 7 - stepper motor; 8 - internal combustion engine; 9 - hydraulic pump; 10 - hydraulic motor; 11 - hydraulic valve; 12 - hydraulic lock; 13 - belt drive.

For the diagram shown in Fig. 1. the required value of the torque on the drive motor shaft $M_{d}$ and its rotation frequency $\omega_{d}$ will be determined taking into account the dependencies given in [6] calculated in accordance with the following formulas

$$
\begin{gathered}
M_{d} \geq k\left(z_{6} / z_{5}\right) n \operatorname{Prhcos}(\beta-\alpha) \sin (\gamma+2 \beta) / u_{r} b \eta, \\
\omega_{d} \geq \omega_{\varphi 0} u_{r}\left(z_{5} / z_{6}\right) / k u_{k},
\end{gathered}
$$

where $k$ - the characteristic of the planetary gear set for the engineering prototype, $k=z_{2} / z_{1}=63 / 33=1,909, z_{6} / z_{5}=27 / 90=0,3$,

$r, h, b$ - size dimensions of the elements of the mechanism [6];

$P$ - the average per cycle (one revolution of the drive shaft) force applied to the crank, depending on $c_{t}, \varphi_{0}$ and the internal gear ratio $i_{t}[1,6]$;

$\beta$ - half the angle of rotation of the crank shaft;

$\gamma$ - the angular position of the guide relative to the vertical axis;

$\alpha$ - the turn angle of the force $P$ from the direction of the radius of the crank;

$u_{r}$ - the gear ratio of the worm gear;

$u_{k}$ - the gear ratio of the rocker arm link (variable value);

$\omega_{\varphi 0}$ - the required rotational speed for changing the vibration amplitude of the rocker arms of the rectifiers, $\omega_{\varphi 0}=\varphi_{0} / \Delta t$.

The value of the mechanism efficiency $\eta$ should be determined using tabulated values of the efficiency of typical mechanisms and corrected using experimental test data for a specific mechanism

$$
\eta=\eta_{r} \eta_{z} \eta_{\rho} \eta_{k}
$$


where $\eta_{r}$ - worm gear efficiency;

$\eta_{z}$ - gearing efficiency $z_{5}, z_{6}$;

$\eta_{\rho}$ - efficiency of the differential planetary gear;

$\eta_{k}$ - efficiency of the rocker arm link.

Fulfilling the conditions laid down in (4) and (5) makes it possible to reasonably choose the power of the drive motor of the Blagonravov transmission control system.

\section{The test results of the experimental drive motor of the Blagonravov transmission control system}

Testing the drive motor of the transmission control system was carried out on the prototype vehicle [5]. The calculation of the work required for twisting the torsion bars according to the formula (1) was $838 \mathrm{~J}$. The calculations were made for the 'stop' mode at $c_{t}=3724$ $\mathrm{Nm} / \mathrm{rad}, n=5$ and $\varphi_{0}=0.3 \mathrm{rad}$. The required rotational speed for changing the vibration amplitude $\varphi_{0}$ of the rocker arms of the rectifiers is $\omega_{\varphi 0}=0.2 \ldots 0.15 \mathrm{rad} / \mathrm{s}$ at $\Delta t=1,5 \ldots 2$ sec. In this case, the required power of the drive motor with disregard for the efficiency is meant to be at least $N=419 \ldots 559 \mathrm{~W}$. When putting the transmission control system into practice, the power of the drive motor is expected to be a bit higher, with due regard for the efficiency.

However, it should be noted that in real vehicle operating conditions the 'stop' mode is practically not found. Typically, as the vehicle speed increases, the rear ends of the torsion bar begin to rotate. The torsion bar twisting decreases and, accordingly, less power of the drive motor is required. In this regard, preliminary tests for working out the control algorithms for the electronic system [3] were carried out with an intentionally lower power of the drive motor.

The simplest system includes an ST86-H150E drive stepper motor with maximum torque of $12.4 \mathrm{Nm}$ (modification I, see Fig. 1). At the same time, an NMRW 063 worm gear with the gear ratio of 20 and the dynamic efficiency of 0.82 is installed in the system. Figure 2.a shows the general view of the installed electric motor with a worm gear (the numbering corresponds to Fig. 1).

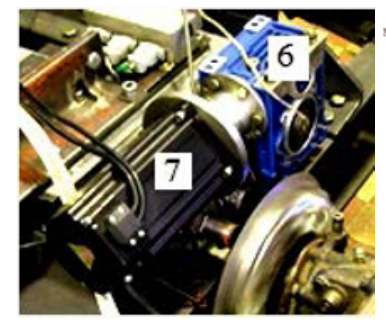

a

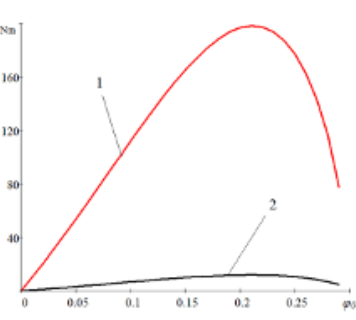

b

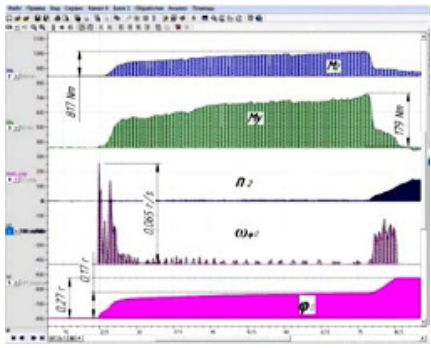

c

Fig. 2. The calculation and test results of the control system with a stepper motor.

a) general view of the electric motor and the worm gear, b) calculated torques on the shafts of the control mechanism, c) fragment of the oscillogram of the control system tests: $\varphi_{0}-$ vibration amplitude of the rectifier rocker arms; $\omega_{\varphi 0}$-rate of increase in the amplitude; $n_{2}$ - speed of rotation of the transmission driven shaft; $M_{y}$ - torque on the worm wheel axis; $M_{2}$ - torque on the transmission driven shaft 
The results of calculating the torque according to (4) on the shaft of this motor in the 'stop' mode $\left(i_{t}=0\right.$ [1]) are shown in Fig. 2.b (line 2). The maximum value of the required torque was $12.08 \mathrm{Nm}$ with the vibration amplitude $\varphi_{0}=0.21 \mathrm{rad}$. The calculated torque $M_{y}$ at point $c$ (see Fig. 1) on the axis of the worm wheel is also shown (see Fig. 2.b, line 1). On the engineering prototype of the transmission the control measurement of the torque is carried out at this point using strain gauges. Fig. 2.c demonstates the fragment of the oscillogram obtained during testing the vehicle in the 'stop' mode. This mode is implemented by holding the vehicle in its place by means of standard brakes. When the brakes are released, the torque $M_{y}$ decreases sharply from $179 \mathrm{Nm}$ (the calculated value is $181 \mathrm{Nm}$, see Fig. 2.b) at $\varphi_{0}=0.17 \mathrm{rad}$ to $62 \mathrm{Nm}$, and the amplitude $\varphi_{0}$ is increased by means of the electric drive to the value of $0.27 \mathrm{rad}$, set by the control pedal. The maximum rate $\omega_{\varphi 0}$ of increasing the amplitude is no more than $0.065 \mathrm{rad} / \mathrm{sec}$, which turned out to be clearly insufficient. This is due to a sharp decrease in torque (according to the characteristic) with an increase in the rotation speed of the ST86-H150E stepper motor. When a more powerful electric motor is used, the overall dimensions of the drive increase significantly, that is undesirable.

Electrohydraulic drive of the control system, made according to modification II (Fig. 1) includes a gerotor type motor of the AHMM40R1CY1 series with a power of $2.4 \mathrm{~kW}$. The torque rating of this motor is $45 \mathrm{Nm}$ with maximum shaft speed of $500 \mathrm{rpm}$ and rated differential pressure of 90 bar. Toyota power steering pump is used as a hydraulic pump. The measured pressure in the system when the internal combustion engine is idling $(500 \ldots$ $600 \mathrm{rpm}$ ) was $80 \ldots 120 \mathrm{bar}$, which is quite enough for the system to function. The circuit uses the worm gear NMRW 063 with the gear ratio of 7.5 and the dynamic efficiency of 0.88 . Figure 3.a demonstrates the general view of the drive (the numbering corresponds to Fig. 1). The results of calculating the torque according to (4), similar to those performed for modification I, are shown in Fig. 3.b (line 2).

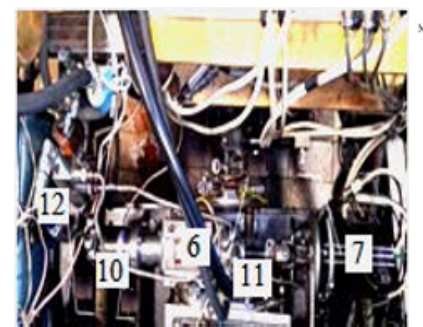

a

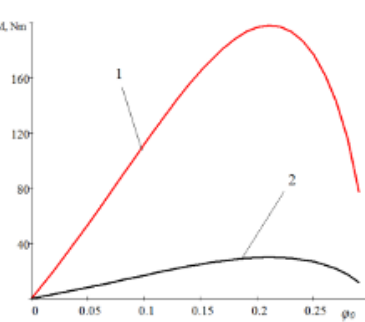

$\mathrm{b}$

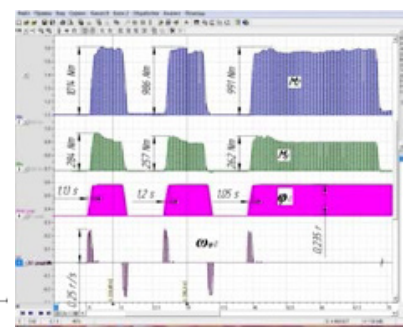

$\mathrm{c}$

Fig. 3. Results of calculation and testing of the control system with an electrohydraulic drive.

a) general view of the elements of the hydraulic system, b) calculated torques on the shafts of the control mechanism, c) fragment of the oscillogram of the control system tests.

The maximum value of the required torque was $30 \mathrm{Nm}$ with the vibration amplitude $\varphi_{0}$ $=0.21 \mathrm{rad}$. The system was tested by quickly pressing and releasing the control pedal. The vehicle wheels were put out of action by means of the standard brakes. The results are shown in Fig. 3.c. The parameters shown in the oscillogram fragment are similar to those shown in Fig. 2.c. The maximum rate $\omega_{\varphi 0}$ of increasing the amplitude was $0.25 \mathrm{rad} / \mathrm{sec}$, which corresponds to the required values. As for the speed of the control system, it is worth noting that the time for increasing the amplitude $\varphi_{0}$ from zero to $0.235 \mathrm{rad}$ was $1.05 \ldots 1.2$ sec, which is more than enough. In this case, the peak value of $M_{y}$ is $262 \ldots 284 \mathrm{Nm}$, which is approximately $20 \ldots 25 \%$ higher than the calculated values. The torque on the 
transmission driven shaft $M_{2}$ is approximately $980 \ldots 1010 \mathrm{Nm}$. Such a transmission control drive will provide the required characteristics of acceleration and movement of the vehicle.

\section{Conclusions}

The results obtained show that an increase in the vibration amplitude of the rectifier rocker arms in the 'stop' mode of the Blagonravov transmission is provided only due to the operation of the drive motor of the control system. This work is used to twist the transmission torsion bars. It is possible to provide the necessary speed of the control system when using an electrohydraulic drive. At the same time, the control system's design turns out to be quite compact and well controlled. The proposed ratios for calculating the required torque and rotational speed of the drive motor shaft make it possible to reasonably choose its power. For the experimental model of the Blagonravov transmission, the power of the drive hydraulic motor of $2.4 \mathrm{~kW}$ provides the required characteristics of the control system. Such system can be recommended when designing the control gear for the Blagonravov continuously variable mechanical transmission.

The research was carried out under the state task No. 0391-2014-007, with partial support from the Institute of Engineering Science of the Russian Academy of Science (Ural Branch). The paper draws upon the materials received within the framework of the grant provided by the Russian Foundation for Basic Research No.16-08-00717 "Developing principles for effective functioning of a new class of continuously variable mechanical transmissions with internal force function", head A. Blagonravov.

\section{References}

1. A. Blagonravov, Mechanical continuously variable transmissions (Yekaterinburg, Ural Branch of the Russian Academy of Sciences Publ., 2005)

2. A. Blagonravov, Russ. Eng. Res., 10, 8 (2011)

3. A. Yurkevich, A. Tereshin, V. Soldatkin, IEEE Xplore Conf. Ind. Eng. and Modern Tech., Far East Con, 8934163 (2019)

4. J. W. Leech, Classical Mechanics (M.: Foreign literature Publ., 1961)

5. A. Tereshin, V. Soldatkin, A. Yurkevich, D. Petrov, Act. prob. of math., mech., comp. science: Conf. of young scientists, 111 (2019)

6. V. Soldatkin, A. Yurkevich, A. Tereshin, IOP Conf. Ser.: Mater. Sci. Eng, 971, 042019 (2020)

7. Y. Yenovskiy-Lashkov, V. Baranov, V. Raskin, K. Melamed, Friction-type continuously variable transmissions of automobiles ( M.: NAMI Publ., 1990)

8. A. Blagonravov, Continuously variable mechanical transmissions of non-friction type (M.: Mashinostroenie Publ., 1977)

9. A. Kropp, Drives of machines with impulse variators (M.: Mashinostroenie Publ., 1988)

10. B. Gasanov, V. Mishustin, Proceedings of Universities, North Caucasian Region, Tech.Sci., 4, 47 (2013) 